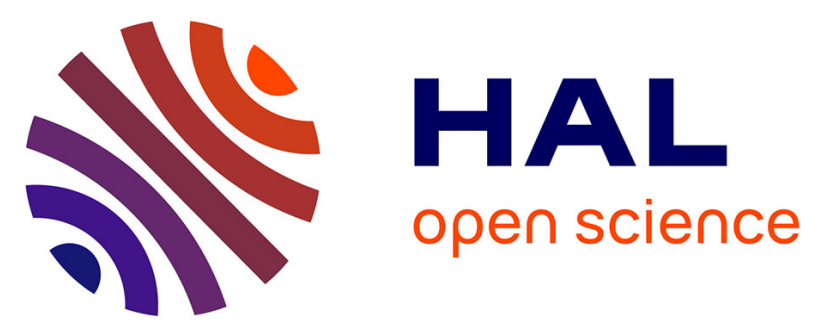

\title{
Sensitization of Er 3 + Infrared Photoluminescence Embedded in a Hybrid Organic-Inorganic Copolymer containing Octahedral Molybdenum Clusters
}

Yann Molard, Christophe Labbé, Julien Cardin, Stéphane Cordier

\section{- To cite this version:}

Yann Molard, Christophe Labbé, Julien Cardin, Stéphane Cordier. Sensitization of Er $3+$ Infrared Photoluminescence Embedded in a Hybrid Organic-Inorganic Copolymer containing Octahedral Molybdenum Clusters. Advanced Functional Materials, 2013, 23 (38), pp.4821-4825. 10.1002/adfm.201300417 . hal-01138686

\section{HAL Id: hal-01138686 \\ https://hal.science/hal-01138686}

Submitted on 6 Apr 2017

HAL is a multi-disciplinary open access archive for the deposit and dissemination of scientific research documents, whether they are published or not. The documents may come from teaching and research institutions in France or abroad, or from public or private research centers.
L'archive ouverte pluridisciplinaire HAL, est destinée au dépôt et à la diffusion de documents scientifiques de niveau recherche, publiés ou non, émanant des établissements d'enseignement et de recherche français ou étrangers, des laboratoires publics ou privés. 


\title{
Sensitization of $\mathrm{Er}^{3+}$ Infrared Photoluminescence Embedded in a Hybrid Organic-Inorganic Copolymer containing Octahedral Molybdenum Clusters
}

\author{
Yann Molard,* Christophe Labbé, Julien Cardin, and Stéphane Cordier
}

\begin{abstract}
Luminescent hybrid copolymers are obtained by copolymerizing in bulk methylmethacrylate with a methacrylic acid (MAC) solution containing [ $n$ $\left.\mathrm{Bu}_{4} \mathrm{~N}\right]_{2}\left[\mathrm{Mo}_{6} \mathrm{Br}_{8}(\mathrm{MAC})_{6}\right.$, and aliquots of an $\mathrm{Er}(\mathrm{TMHD})_{3}$ complex (TMHD for 2,2,6,6-tetramethyl-3,5-heptanedione) solution. This leads to novel homogeneous and transparent hybrid materials in which the $\mathrm{Er}^{3+}$ infrared luminescence at $1.55 \mu \mathrm{m}$, a standard wavelength for telecommunication applications, is up to six time more intense in the presence of $\mathrm{Mo}_{6}$ clusters when samples are irradiated at $476.5 \mathrm{~nm}$. This work demonstrates the outstanding potential of $\mathrm{Mo}_{6}$ clusters, compounds obtained by high-temperature solid-state synthesis, in the design of functional hybrid materials via soft chemistry routes.
\end{abstract}

leading to inefficient emission from the
rare earth $4 \mathrm{f}$ levels under direct excitation.
One strategy to overcome the limitation
of this class of materials is the design of
organic/inorganic polymer-based devices.
In this frame, Slooff et al. ${ }^{[4]}$ and Kuriki et
al. ${ }^{[5]}$ pointed out that, beside improving
production cost, fabrication processing,
and generating polymers which possess
high mechanical and thermal stability,
special attention should be drawn to
improving the fluorescence of lanthanide
ions. Two approaches can be developed to
meet these needs: the first one consists
of the coordination of highly absorbing organic antenna groups around the rare earth trivalent cation to increase the pump efficiency, while the second involves using a $\mathrm{SiO}_{2}$ matrix as host for rare-earth ions. This last strategy can be achieved by introducing $\mathrm{Er}^{3+}$-doped silica colloidal spheres in organic polymers. A severe limitation to the first approach is that organic antennas are highly sensitive to premature aging under irradiation, whereas the second approach is negatively impacted by the fact that an efficient rare-earth cross-section absorption in the colloid cannot be obtained without sensitizers.

We propose in this manuscript an alternative and innovative approach to obtain an easily processable material containing $\mathrm{Er}^{3+}$ and having luminescence which is sensitized by phosphorescent octahedral metal atom clusters incorporated in a host organic matrix.

Metal atom clusters are inorganic molecular species obtained via solid-state chemistry routes containing metal atoms linked together by metal-metal bonds. Many routes ${ }^{[6]}$ now afford soluble discrete $\left[M_{6} Q_{8}^{i} X_{6}^{a}\right]^{2-}$ units ( $X=$ halogen) that exhibit, either in the liquid or solid state, specific electronic, magnetic, and photophysical properties related to the number of metallic electrons available for metal-metal bonds. ${ }^{[7]}$ In particular, they are highly emissive in the rednear infrared (NIR) region, have photoluminescence quantum yields of up to 0.23 , and display long excited-state lifetimes. ${ }^{[8]}$ Owing to the stronger covalent nature of the $M-Q^{i}$ bond relative to the $M-X^{a}$ one, halogen apical atoms can be replaced by inorganic or organic ligands without any alteration of the $\left(M_{6} Q_{8}^{i}\right)^{m+}$ core, leading to functional building blocks usable for the design of liquid crystalline material, ${ }^{[9]}$ supramolecular architectures, ${ }^{[10]}$ polymeric frameworks, ${ }^{[11]}$ or nanomaterials ${ }^{[12]}$ with unique properties. In order to obtain $\mathrm{M}_{6}$ clusters containing material suitable for realistic applications, we incorporated them in a poly(methyl methacrylate) (PMMA) matrix

DOI: $10.1002 /$ adfm.201300417 
and investigated the optical properties of the resulting hybrid material. PMMA was chosen for its excellent optical properties (i.e., transparency from the near-UV to the near-IR regions), damage resistance in the range needed for optical applications, good mechanical properties, thermal stability, and easy shaping. A major challenge in the preparation of such hybrid materials is the prevention of phase separation and aggregation of the inorganic species in the host matrix. A few examples are found in the literature where polymers showing stable luminescence properties are obtained by incorporation of octahedral clusters. Shriver et al. ${ }^{[13]}$ coordinated $\left[\mathrm{Mo}_{6} \mathrm{Cl}_{8}(\mathrm{OTf})_{6}\right]^{2-}$ and $\left[\mathrm{Mo}_{6} \mathrm{Cl}_{8}{ }^{i} \mathrm{Cl}_{4}{ }^{a}(\mathrm{EtOH})^{a}{ }_{2}\right]$ to poly(vinylpyridine) (PVP) to produce crosslinked materials. Transient emission spectroscopy revealed that polymer bound hexatriflate cluster lacks the luminescence properties characteristic of many $\left[\mathrm{Mo}_{6} \mathrm{Cl}_{8}\right]^{4+}$ -based clusters while the other one displays luminescence. A similar result was obtained by Jackson et al. ${ }^{[11 \mathrm{~b}]}$ who showed that the PVP- $\mathrm{Mo}_{6} \mathrm{Cl}_{12}$ system could be employed for oxygen sensing or photo-oxidation applications. Here, we develop a simple technique for the synthesis of transparent $\mathrm{PMMA}^{-\mathrm{Mo}_{6}}$ hybrids with stable luminescence properties, and their analogues containing $\mathrm{Er}^{3+}$ complexes. We demonstrate for the first time an effective transfer between transition metal clusters and $\mathrm{Er}^{3+}$ complexes within the polymer that will allow the development of new families of optical amplifiers using lowcost excitation sources.

\section{Results and Discussion}

The choice of $\mathrm{Mo}_{6}$ clusters was driven by their superior luminescence properties, in terms of quantum yield, as compared to their $\mathrm{Re}_{6}$ analogues. ${ }^{[8 \mathrm{~b}, 14]}$ The synthetic approach is based on our recent studies developed for the design of clustomesogen ${ }^{[9 a, 9 b]}$ and on the solvent as monomer approach described by Golden et al. ${ }^{[11 a]}$ It consists of the preparation of a mother liquor containing a $\left[n-\mathrm{Bu}_{4} \mathrm{~N}_{2}\left[\mathrm{Mo}_{6} \mathrm{Br}_{8} \mathrm{~F}_{6}\right]\right.$ cluster precursor and methacrylic acid, aliquots of which are mixed with methylmethacrylate (MMA) and subsequently copolymerized by a radical process using AIBN (0.02 wt\%) as initiator. Several samples containing from 0 to $0.36 \mathrm{wt} \%$ of cluster $\left(\operatorname{Ref}_{1}\right.$, A1-5) were synthesized by this bulk polymerization process. The full dissolution of $\left[n-\mathrm{Bu}_{4} \mathrm{~N}_{2}\left[\mathrm{Mo}_{6} \mathrm{Br}_{8} \mathrm{~F}_{6}\right]\right.$ in methacrylic acid is obtained by a gentle heating of the mixture, giving a highconcentration cluster mother solution $(c=0.015 \mathrm{M}) .{ }^{19} \mathrm{~F}$ NMR in $\mathrm{d}^{6}$-acetone of this solution revealed the complete disappearance of the signal assigned to the starting cluster located around $-188 \mathrm{ppm}$. Thus, heating the cluster mother solution induces an acid-base reaction between methacrylic acid molecules and the fluorinated clusters, leading to grafting in the apical position and, via covalent Mo-O bond formation, six methacrylate moieties with liberation of HF..$^{[9 a, 9 b]}$ As shown in Figure 1, the resulting hybrid polymers are fully optically transparent materials, indicating the absence of macroscopic segregation of the inorganic moieties in the organic matrices. Note that this segregation was observed when $\left[n-\mathrm{Bu}_{4} \mathrm{~N}\right]_{2}\left[\mathrm{Mo}_{6} \mathrm{Br}_{14}\right]$ was used instead of $\left[n-\mathrm{Bu}_{4} \mathrm{~N}\right]_{2}\left[\mathrm{Mo}_{6} \mathrm{Br}_{8} \mathrm{~F}_{6}\right]$, meaning that strong interactions (in our case a covalent linking) between clusters and the organic matrix are mandatory to prevent phase separation.

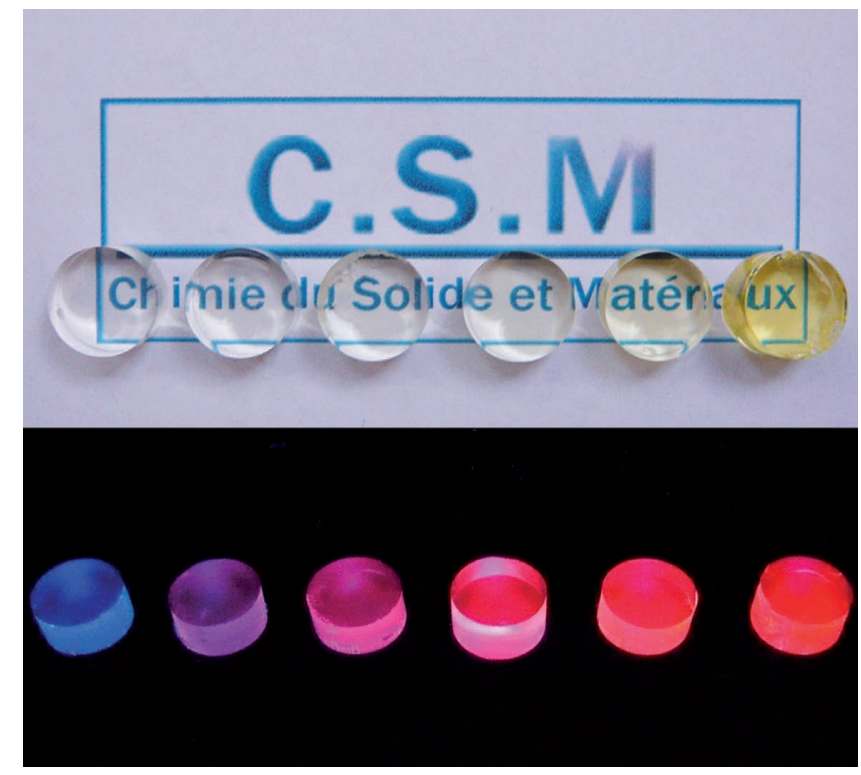

Figure 1. Digital photographs of the $\mathrm{Mo}_{6}-\mathrm{PMMA}$ hybrid copolymer pellets under visible (top) and UV light (bottom); $\lambda_{\text {exc }}=365 \mathrm{~nm}$; cluster concentrations range from 0 to $0.36 \mathrm{wt} \%$ from left to right.

The hybrid materials thermal behavior was examined by thermogravimetric analysis (TGA) and differential scanning calorimetry (DSC) under $\mathrm{N}_{2}$ atmosphere. Size exclusion chromatography (SEC) was also used to further characterize the doped polymers (see the Supporting Information, Figures S1-3). Table 1 summarizes the thermal data and molecular weight calculations obtained by these techniques for all samples. While the obtained pure PMMA has a glass transition temperature $\left(T_{\mathrm{g}}\right)$ comparable to that of commercial PMMA, the introduction of small amounts of clusters drops it dramatically. This phenomenon is attributed to a plasticizing effect induced by an increase in the distance between the polymer chains. ${ }^{[15]}$ By increasing the cluster amount within the copolymer, the $T_{\mathrm{g}}$ and $M_{\mathrm{w}}$ increase, showing that the clusters are covalently linked to the polymer strands and act as cross-linking agents. Moreover, if pure PMMA and pellets from A1 to A3 were completely soluble in tetrahydrofuran (THF), pellet A4 could not be entirely dissolved while pellet A5 was not soluble and started

Table 1. Thermal data for copolymer samples.

\begin{tabular}{lccccc}
\hline & $\begin{array}{c}\text { Amount of cluster } \\
{[\mathrm{wt} \%]}\end{array}$ & $\begin{array}{c}\text { [Cluster] } \\
{[\text { molecules cm }}\end{array}$ & $\begin{array}{c}T_{\mathrm{g}} \\
{\left[{ }^{\circ} \mathrm{C}\right]^{\mathrm{a})}}\end{array}$ & $\begin{array}{c}T_{\mathrm{d}} \\
{\left[{ }^{\circ} \mathrm{C}\right]^{\mathrm{b})}}\end{array}$ & $\begin{array}{c}M_{\mathrm{w}} \\
\left.\left[\mathrm{g} \mathrm{mol}^{-1}\right]^{\mathrm{c}}\right)\end{array}$ \\
\hline Ref $_{1}$ & 0 & 0 & 123.8 & 377 & 495000 \\
$\mathrm{~A} 1$ & 0.018 & $0.56 \times 10^{17}$ & 92.5 & 387 & 705500 \\
$\mathrm{~A} 2$ & 0.044 & $1.36 \times 10^{17}$ & 100.8 & 391 & 981000 \\
A3 & 0.09 & $2.79 \times 10^{17}$ & 123.6 & 395 & 987000 \\
A4 & 0.18 & $5.57 \times 10^{17}$ & 110.5 & 400 & 456500 \\
A5 & 0.36 & $11.14 \times 10^{17}$ & 109.5 & 412 & - \\
\hline
\end{tabular}

a) Glass transition temperature; b) decomposition temperature; c)average molecular weight. 
to swell in this solvent, confirming the clusters cross-linking ability as well as the chemical stability of the cluster-polymer bonds in solution.

The influence of the cluster concentration on the $\mathrm{Mo}_{6}$ PMMA copolymer thermal stability was studied by comparing the degradation temperatures of all samples under $\mathrm{N}_{2}$ atmosphere (see the Supporting Information for TGA and differential thermal analysis (DTA) thermograms). A small weight loss $(<2.5 \%)$ starting around $80{ }^{\circ} \mathrm{C}$ due to the evaporation of unreacted monomers was observed for all samples, meaning that the polymerization process is not complete under our conditions. This point is corroborated by the detection of traces of monomers during the SEC experiments (see the Supporting Information). The main reaction stage corresponding to the maximum weight loss is located at $377^{\circ} \mathrm{C}$ for pure PMMA. This maximum is shifted to higher temperature for higher cluster content, showing that the thermal stability of hybrid copolymers is significantly improved as compared to pure PMMA and evidencing once again the cross-linking ability of the modified cluster as well as its stability within the polymer matrix.

Optical properties determinations were investigated directly on the $5 \mathrm{~mm}$ thick copolymer pellets. Transmittance measurements (see the Supporting Information) showed the typical cut off of PMMA in the UV region under $300 \mathrm{~nm}$, while the doped polymer pellets transmittance spectra revealed a shoulder around $400 \mathrm{~nm}$ increasing with the cluster amount present in the pellets (Supporting Information, Figure S4a). Luminescence measurements were realized in the solid state directly on the doped polymer pellets and revealed the apparition of a broad and structure-less emission band extending from 560 to more than $900 \mathrm{~nm}$ and centered around $\lambda_{\mathrm{em}}=710 \mathrm{~nm}$ (Supporting Information, Figure S4b). For all pellets, the emission maximum is slightly shifted to lower wavelength $(\Delta \lambda=35 \mathrm{~nm})$ when compared to the $\left[n-\mathrm{Bu}_{4} \mathrm{~N}_{2}\left[\mathrm{Mo}_{6} \mathrm{Br}_{8} \mathrm{~F}_{6}\right]\right.$ emission spectrum, as observed in a previous case when carboxylate derivatives were grafted on the six apical positions of the inorganic core. ${ }^{[9]}$ A luminescence absolute quantum yield of 0.15 at $\lambda_{\text {exc }}=360 \mathrm{~nm}$ was calculated by using a Hamamatsu Quantaurus-QY system, which is nearly double the previous reported value for $\mathrm{M}_{6}$ clusters embedded in a PMMA matrix. ${ }^{[11 d]}$ At this stage we must emphasize that these properties are kept after 72 months of aging, attesting to the outstanding stability of the copolymer that is a prerequisite for the design of functional devices, and validating our approach.

Taking into consideration that stability and processability of the hybrid copolymers are prerequisites for the design of optical amplifiers, we synthesized $\mathrm{Er}^{3+}-\mathrm{Mo}_{6}-\mathrm{PMMA}$ materials containing various amount of $\mathrm{Er}^{3+}$ complexes $(0.5,0.90$, or 1.3 wt $\%)$ with $\left(\mathrm{P}_{x \mathrm{C}}\right)$ or without $\left(\mathrm{P}_{x}\right) 0.25 \mathrm{wt} \%$ of clusters. Several samples were thus prepared, using the same bulk copolymerization process as previously described but adding aliquots of a concentrated dichloromethane solution of $\operatorname{Er}(\mathrm{TMHD})_{3}$ complex (TMHD for 2,2,6,6-tetramethyl-3,5-heptanedione) in the monomer mixtures prior to copolymerization. A pellet of pure PMMA $\left(\operatorname{Ref}_{2}\right.$ ) was also synthesized for comparison purposes. Compositions of prepared samples are summarized in Table 2.

TGA measurements (see the Supporting Information) showed that the integration of Er complexes has little influence on the copolymer samples' thermal stability. Indeed, only weak
Table 2. Summary of the prepared copolymer samples composition.

\begin{tabular}{lccccc}
\hline & $\begin{array}{c}\mathrm{Er}^{3+} \\
{[\mathrm{wt} \%]}\end{array}$ & $\left.\begin{array}{c}{\left[\mathrm{Er}^{3+}\right][\mathrm{mol}-} \\
\text { ecules cm }\end{array}{ }^{-3}\right]$ & $\begin{array}{c}\text { Clusters } \\
{[\mathrm{wt} \%]}\end{array}$ & $\begin{array}{c}\text { [Cluster }] \\
{\left[\text { molecules } \mathrm{cm}^{-3}\right]}\end{array}$ & $\begin{array}{c}\mathrm{T}_{\mathrm{d}} \\
{\left[{ }^{\circ} \mathrm{C}\right]}\end{array}$ \\
\hline $\mathrm{P}_{0.5}$ & 0.50 & $4.2 \times 10^{18}$ & 0 & 0 & 390 \\
$\mathrm{P}_{0.9}$ & 0.90 & $7.1 \times 10^{18}$ & 0 & 0 & 390 \\
$\mathrm{P}_{1.3}$ & 1.30 & $10.1 \times 10^{18}$ & 0 & 0 & 390 \\
$\mathrm{P}_{0.5 \mathrm{C}}$ & 0.50 & $4.2 \times 10^{18}$ & 0.25 & $7.74 \times 10^{17}$ & 410 \\
$\mathrm{P}_{0.9 \mathrm{C}}$ & 0.90 & $7.1 \times 10^{18}$ & 0.25 & $7.74 \times 10^{17}$ & 410 \\
$\mathrm{P}_{1.3 \mathrm{C}}$ & 1.30 & $10.1 \times 10^{18}$ & 0.25 & $7.74 \times 10^{17}$ & 410 \\
Ref $_{2}$ & 0 & 0 & 0 & 0 & 380 \\
\hline
\end{tabular}

interactions exist between the $\mathrm{Er}^{3+}$ complexes and the organic matrix whereas clusters are covalently bonded to PMMA. Therefore $\mathrm{Er}^{3+}$-containing polymers keep the processability of PMMA.

Optical properties were measured in this case on $1.90 \pm$ $0.03 \mathrm{~mm}$ thick pellets (Figure 2 shows pellets $\mathrm{P}_{1.3}, \mathrm{P}_{0.5 \mathrm{C}}$, and $\mathrm{P}_{1.3 \mathrm{C}}$ under normal and UV light). At first sight, one can notice a difference in the red luminescence upon UV excitation of $\mathrm{P}_{0.5 \mathrm{C}}$ and $\mathrm{P}_{1.3 \mathrm{C}}$ pellets, illustrating the influence of $\mathrm{Er}^{3+}$ content on the visible emission properties of $\mathrm{Mo}_{6}$ clusters.

Figure 3 presents absorption spectra of pure PMMA, $\mathrm{Er}^{3+}$ containing, and, $\mathrm{Er}^{3+}$ and $\mathrm{Mo}_{6}$ cluster-containing samples. If these pellets have similar absorption behaviours in the IR and NIR area, they keep the particularities of their individual components in the UV-vis region. Emission measurements were realized at room temperature using an Argon Laser as the excitation source with a $476.5 \mathrm{~nm}$ irradiation wavelength. Thought this wavelength is not the optimum one to observe an intense cluster luminescence. It was chosen because it overlaps only very weakly with $\mathrm{Er}^{3+}$ absorption bands.

As depicted in Figure $4 \mathrm{a}$, irradiation of $\mathrm{P}_{x}$ pellets induces a very weak and broad emission with a maximum centered around $1530 \mathrm{~nm}$ characteristic of the ${ }^{4} \mathrm{I}_{13 / 2} \rightarrow{ }^{4} \mathrm{I}_{15 / 2} \mathrm{Er}^{3+}$ transition. This emission could either be due to a weak absorption of the excitation wavelength by the ${ }^{4} \mathrm{I}_{15 / 2} \rightarrow{ }^{4} \mathrm{~F}_{7 / 2}$ transition located

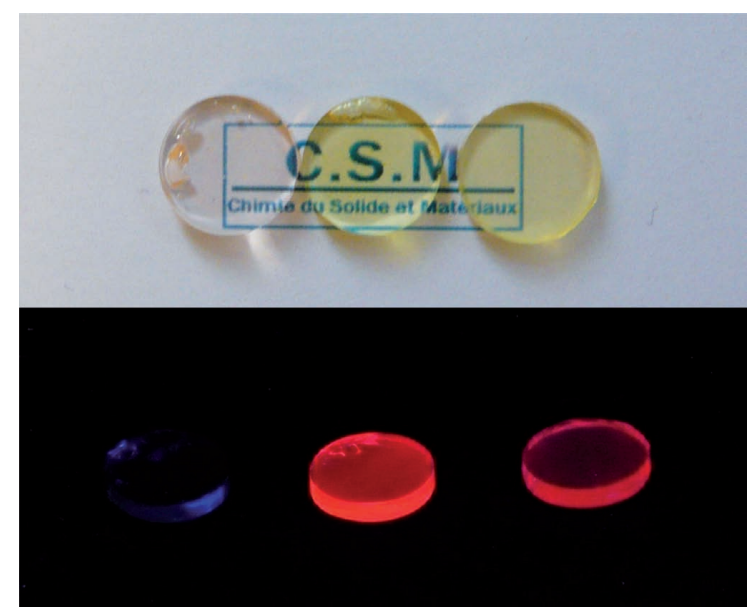

Figure 2. Digital photographs of hybrid copolymer pellets $\mathrm{P}_{1.3}, \mathrm{P}_{0.5 \mathrm{C}}$, and $P_{1.3 \mathrm{C}}$ under visible (top) and UV $\left(\lambda_{\mathrm{exc}}=365 \mathrm{~nm}\right)$ irradiation (bottom). 


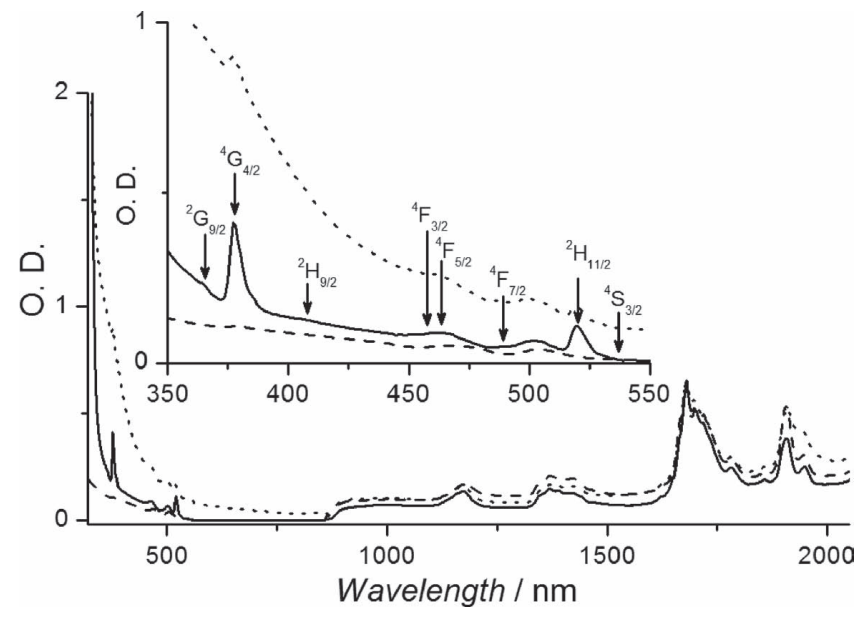

Figure 3. Solid state absorption spectra of $P_{13}$ (plain line), $P_{13 c}$ (dotted line), and $\operatorname{Ref}_{2}$ (dashed line) pellets.

around $483 \mathrm{~nm}$ or by an energy transfer from the organic matrix to the $\mathrm{Er}^{3+}$ ion. ${ }^{[16]}$ The broadening of the emission is associated to the coupling of $\mathrm{f}-\mathrm{f}$ electronic transition of erbium with vibrational modes of the PMMA matrix.

One can notice that if the observed emission intensities seem proportional to the $\mathrm{Er}^{3+}$ content in $\mathrm{P}_{0.5}$ and $\mathrm{P}_{0.9}, \mathrm{P}_{1.3}$ emits approximately the same amount of photons as $\mathrm{P}_{0.9}$. As our $\mathrm{Er}^{3+}$ working concentration is low compared to previous reported results, we attribute this phenomenon to a self aggregation process of $\mathrm{Er}^{3+}$ complexes within the host matrix instead of some

a)

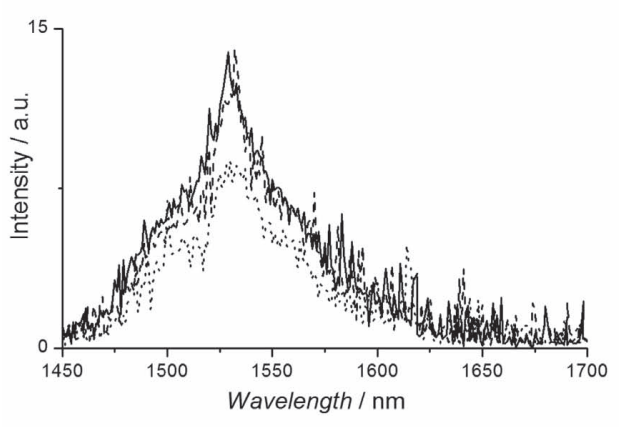

c)

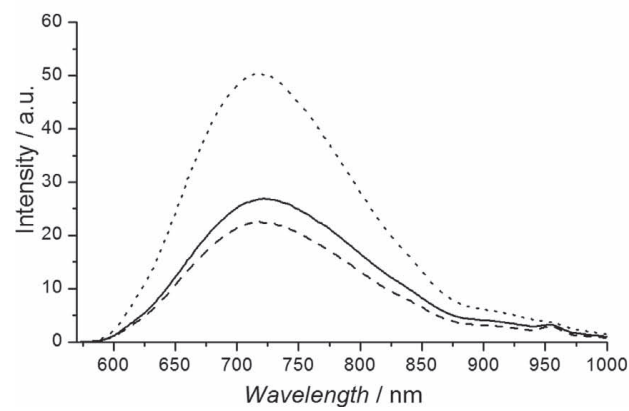

quenching phenomena induced by cooperative up-conversion and resonant energy transfer which should occur for higher concentrations. ${ }^{[17]}$ It confirms the existence of an optimum concentration of $\mathrm{Er}^{3+}$ complexes within the polymer matrix that was not determined in the scope of these investigations. Figures $4 c, d$ represent the emission spectra of $\mathrm{P}_{x \mathrm{C}}$ pellets either in the visible (4c) or IR (4d) area. Increasing the $\mathrm{Er}^{3+} \mathrm{com}$ plex concentration induces a decrease of the cluster emission together with a large increase of $\mathrm{Er}^{3+}$ complex in the IR region, showing the existence of an effective transfer between the two species. This phenomenon is best seen on Figure $4 \mathrm{~b}$, where the IR $\mathrm{Er}^{3+}$ complex emissions without $\left(\mathrm{P}_{1.3}\right)$ or with $\left(\mathrm{P}_{1.3 \mathrm{C}}\right)$ cluster are superimposed. Indeed the emission in the IR is enhanced because of cluster $\mathrm{Er}^{3+}$ sensitization. This sensitization allows an emission improvement by a factor 4 to 6 depending on the samples (inset Figure $4 \mathrm{~b}$ ). Even though this improvement is still weak for application purposes, it demonstrates for the first time the possibility to sensitize IR emission of trivalent rareearth metal complexes with transition metal clusters within a transparent and easily processable organic matrix.

\section{Conclusions}

We have described in this manuscript a simple method to obtain $\mathrm{Mo}_{6}$-PMMA copolymer samples within which $\mathrm{Mo}_{6}$ clusters keep their intrinsic luminescence properties. These emissive properties have been used successfully to sensitize trivalent $\mathrm{Er}^{3+}$ complex emission in the infrared region and within the polymer matrix. Indeed, introduction of $0.25 \mathrm{wt} \%$ of metallic

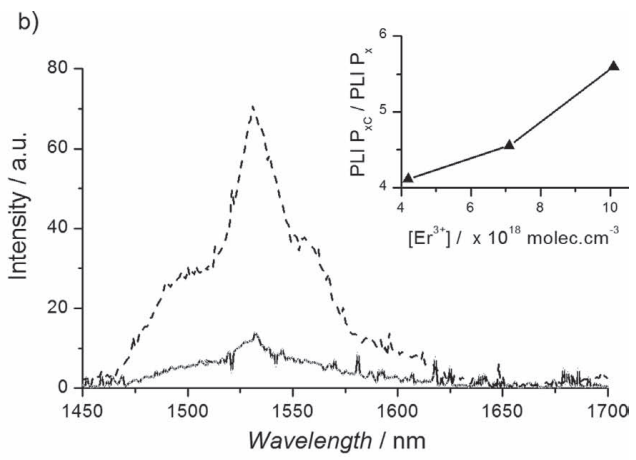

d)

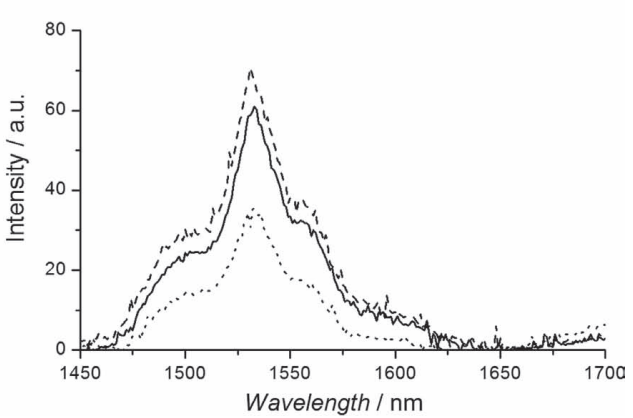

Figure 4. Solid state luminescence properties at $25{ }^{\circ} \mathrm{C}$ upon excitation at $\lambda_{\text {exc }}=476.5 \mathrm{~nm}$ of: a) pellets $P_{0.5}$ (dotted line), $P_{0.9}$ (solid line), and $P_{1.3}$ (dashed line); b) pellets $P_{1.3}$ (solid line) and $P_{1.3 c}$ (dotted line) (inset: photoluminescence intensity ratio between $P_{x c}$ and $P_{x}$ samples); c,d) pellets $P_{0.5 C}$ (dotted line), $\mathrm{P}_{0.9 \mathrm{C}}$ (solid line), and $\mathrm{P}_{1.3 \mathrm{C}}$ (dashed line). 
cluster induces increases by factors from 4 to 6 of the $\mathrm{Er}^{3+}$ transition at $1.5 \mu \mathrm{m}$ wavelength, thus validating the concept of trivalent rare-earth metal infrared luminescence sensitization by transition metal clusters. Although further investigations are ongoing to maximize this sensitization, this first study offers promising perspectives in the design of easy-to-handle $\mathrm{Er}^{3+}$ -containing materials suitable for excitation using cheap optical illumination systems directed towards telecom applications.

\section{Experimental Section}

Starting materials were purchased from Alfa Aesar or Aldrich. Methacrylic acid and methyl methacrylate were distilled before use. Azobisizobutyronitryle (AIBN) was purified via recrystallization in ether prior to use. ( $n-\mathrm{Bu} 4 \mathrm{~N}) 2[\mathrm{Mo6} \mathrm{Br} 8 \mathrm{~F} 6]$ precursor was obtained by a procedure reported elsewhere. ${ }^{[18]}$ The full dissolution of [n-Bu4N]2[Mo6Br8F6] in methacrylic acid was obtained by a gentle heating of the mixture, giving a high-concentration cluster solution $(c=0.015 \mathrm{M})$.

A Series: Aliquots of the cluster mother liquor and methyl methacrylate monomers were poured into a test tube to give a mixture weighing $1.5 \mathrm{~g}$. After addition of the radical initiator (AIBN, $0.02 \mathrm{wt} \%$ ), the homogeneous solution was kept at $60{ }^{\circ} \mathrm{C}$ in an ultrasonic bath for $3 \mathrm{~h}$ and allowed to stand at $60^{\circ} \mathrm{C}$ for $72 \mathrm{~h}$.

$P x$ and PxC Series: $\operatorname{Er}(\mathrm{TMHD}) 3$ complex (TMHD for 2,2,6,6-tetramethyl-3,5-heptanedione; 10, 17, or $24 \mathrm{mg}$ ) was placed in a sample tube and solubilized with a few drops of distilled $\mathrm{CH}_{2} \mathrm{Cl}_{2}$. Methyl methacrylate, clusters dissolved in methacrylic acid, and AIBN $(0.02$ $\mathrm{wt} \%)$ were added to the test tubes to reach a total weight of $2 \mathrm{~g}$. The homogeneous solutions were kept at $60^{\circ} \mathrm{C}$ in an ultrasonic bath for $3 \mathrm{~h}$ and allowed to stand at $60^{\circ} \mathrm{C}$ for $72 \mathrm{~h}$.

\section{Supporting Information}

Supporting Information is available from the Wiley Online Library or from the author.

\section{Acknowledgements}

The authors thank Dr. R. Rizk from CIMAP Caen for useful discussions and Dr. Jocelyne Galy From LIMP UMR CNRS 5223 Insa Lyon for SEC measurements. This work was financially supported by the Fondation Langlois and GDR2975-C'Nano Nord Ouest.

[1] R. Noé, Essentials of Modern Optical Fiber Communication, Springer, Berlin/Heidelberg 2010.

[2] K. Binnemans, Chem. Rev. 2009, 109, 4283.

[3] a) D. Bayart, C. R. Phys. 2003, 4, 65; b) S. Frolov, S. Tek-Ming, A. J. Bruce, Proc. SPIE 2003, 47, 4990.

[4] L. H. Slooff, A. van Blaaderen, A. Polman, G. A. Hebbink, S. I. Klink, F. C. J. M. Van Veggel, D. N. Reinhoudt, J. W. Hofstraat, J. Appl. Phys. 2002, 91, 3955.

[5] K. Kuriki, Y. Koike, Y. Okamoto, Chem. Rev. 2002, 102, 2347.

[6] a) J. R. Long, L. S. McCarty, R. H. Holm, J. Am. Chem. Soc. 1996, 118,4603 ; b) K. Kirakci, S. Cordier, C. Perrin, Z. Anorg. Allg. Chem. 2005, 631, 411 .
[7] a) R. Chevrel, M. Sergent, in Topics in Current Physics (Eds.: O. Fischer, M. P. Maple), Springer Verlag, Berlin, 1982; b) D. G. Nocera, H. B. Gray, J. Am. Chem. Soc. 1984, 106, 824; c) J. M. Tarascon, F. J. Disalvo, D. W. Murphy, G. W. Hull, E. A. Rietman, J. V. Waszczak, J. Solid State Chem. 1984, 54, 204.

[8] a) A. W. Maverick, H. B. Gray, J. Am. Chem. Soc. 1981, 103, 1298; b) A. W. Maverick, J. S. Najdzionek, D. MacKenzie, D. G. Nocera, H. B. Gray, J. Am. Chem. Soc. 1983, 105, 1878.

[9] a) Y. Molard, F. Dorson, V. Circu, T. Roisnel, F. Artzner, S. Cordier, Angew. Chem., Int. Ed. 2010, 49, 3351; b) A. S. Mocanu, M. Amela-Cortes, Y. Molard, V. Circu, S. Cordier, Chem. Commun. 2011, 47, 2056; c) Y. Molard, A. Ledneva, M. Amela-Cortes, V. Circu, N. G. Naumov, C. Meriadec, F. Artzner, S. Cordier, Chem. Mater. 2011, 23, 5122.

[10] a) Z. N. Chen, T. Yoshimura, M. Abe, Y. Sasaki, S. Ishizaka, H. B. Kim, N. Kitamura, Angew. Chem., Int. Ed. 2001, 40, 239; b) H. D. Selby, B. K. Roland, Z. Zheng, Acc. Chem. Res. 2003, 36, 933; c) D. Mery, C. Ornelas, M.-C. Daniel, J. Ruiz, J. Rodrigues, D. Astruc, S. Cordier, K. Kirakci, C. Perrin, C. R. Chim. 2005, 8, 1789; d) G. Prabusankar, Y. Molard, S. Cordier, S. Golhen, Y. Le Gal, C. Perrin, L. Ouahab, S. Kahlal, J. F. Halet, Eur. J. Inorg. Chem. 2009, 2153; e) F. Dorson, Y. Molard, S. Cordier, B. Fabre, O. Efremova, D. Rondeau, Y. Mironov, V. Circu, N. Naumov, C. Perrin, Dalton Trans. 2009, 1297.

[11] a) J. H. Golden, H. B. Deng, F. J. Disalvo, J. M. J. Frechet, P. M. Thompson, Science 1995, 268, 1463; b) J. A. Jackson, M. D. Newsham, C. Worsham, D. G. Nocera, Chem. Mater. 1996, 8, 558; c) M. A. Shestopalov, S. Cordier, O. Hernandez, Y. Molard, C. Perrin, A. Perrin, V. E. Fedorov, Y. V. Mironov, Inorg. Chem. 2009, 48, 1482; d) Y. Molard, F. Dorson, K. A. Brylev, M. A. Shestopalov, Y. Le Gal, S. Cordier, Y. V. Mironov, N. Kitamura, C. Perrin, Chem. Eur. J. 2010, 16, 5613.

[12] a) S. Ababou-Girard, S. Cordier, B. Fabre, Y. Molard, C. Perrin, ChemPhysChem 2007, 8, 2086; b) F. Grasset, F. Dorson, S. Cordier, Y. Molard, C. Perrin, A.-M. Marie, T. Sasaki, H. Haneda, Y. Bando, M. Mortier, Adv. Mater. 2008, 20, 143; c) F. Grasset, F. Dorson, Y. Molard, S. Cordier, V. Demange, C. Perrin, V. Marchi-Artzner, H. Haneda, Chem. Commun. 2008, 4729; d) F. Grasset, Y. Molard, S. Cordier, F. Dorson, M. Mortier, C. Perrin, M. Guilloux-Viry, T. Sasaki, H. Haneda, Adv. Mater. 2008, 20, 1710; e) S. Cordier, F. Dorson, F. Grasset, Y. Molard, B. Fabre, H. Haneda, T. Sasaki, M. Mortier, S. Ababou-Girard, C. Perrin, J. Clust. Sci. 2009, 20, 9; f) B. Fabre, S. Cordier, Y. Molard, C. Perrin, S. Ababou-Girard, C. Godet, J. Phys. Chem. C 2009, 113, 17437; g) T. Aubert, F. Grasset, S. Mornet, E. Duguet, O. Cador, S. Cordier, Y. Molard, V. Demange, M. Mortier, H. Haneda, J. Colloid Interface Sci. 2010, 341, 201; h) T. Aubert, A. Y. Ledneva, F. Grasset, K. Kimoto, N. G. Naumov, Y. Molard, N. Saito, H. Haneda, S. Cordier, Langmuir 2010, 26, 18512; i) D. Dybtsev, C. Serre, B. Schmitz, B. Panella, M. Hirscher, M. Latroche, P. L. Llewellyn, S. Cordier, Y. Molard, M. Haouas, F. Taulelle, G. Ferey, Langmuir 2010, 26, 11283; j) V. Roullier, V. Marchi-Artzner, O. Cador, F. Dorson, T. Aubert, S. Cordier, Y. Molard, F. Grasset, S. Mornet, H. Haneda, Int. J. Nanotechnol. 2010, 7, 46.

[13] L. M. Robinson, D. F. Shriver, J. Coord. Chem. 1996, 37, 119.

[14] T. G. Gray, C. M. Rudzinski, E. E. Meyer, R. H. Holm, D. G. Nocera, J. Am. Chem. Soc. 2003, 125, 4755.

[15] F. Girardi, F. Graziola, P. Aldighieri, L. Fedrizzi, S. Gross, R. Di Maggio, Prog. Org. Coat. 2008, 62, 376.

[16] R. S. Fonseca, M. Flores, R. Rodriguez, J. Hernandez, A. Munoz, J. Lumin. 2001, 93, 327.

[17] A. Q. Le Quang, E. Besson, R. Hierle, A. Mehdi, C. Reye, R. Corriu, I. Ledoux-Rak, Opt. Mater. 2007, 29, 941.

[18] W. Preetz, D. Bublitz, H. G. Vonschnering, J. Sassmannshausen, Z. Anorg. Allg. Chem. 1994, 620, 234. 